\section{Cuidados primários, avaliação e ações intersetoriais em promoção da saúde}

Primary care, evaluation and intersectoral actions in health promotion

\section{Zulmira M. A. Hartz ${ }^{1}$}

Pode ser, ainda, que experiências de governança da ação intersectorial venham a contribuir para o grande debate sobre a Agenda do Desenvolvimento Sustentável, mas Manguinhos já tem o que dizer com sua experiência de governança local para o desenvolvimento, que este livro com muita propriedade avalia ${ }^{1}$.

Inicialmente agradeço a querida Cecília Minayo este convite privilegiado para fazer um breve comentário ao criterioso e bem documentado trabalho analítico, de Daniel Soranz e Luis Pisco, sobre a reforma carioca e lisboeta dos cuidados primários em saúde. Considerando o respeito ao espaço editorial para este fim e minha vivência recente em Portugal, gostaria apenas de realçar a valiosa investigação avaliativa da sua entidade reguladora de saúde e o sistema de acreditação, excelente narrativa de boas práticas implementadas em âmbito nacional. Vou limitar-me portanto a comentar a experiência da Fiocruz no território de Manguinhos, pois, embora tendo sido referida sua parceria com a Secretaria Municipal de Saúde do Rio de Janeiro no ensino técnico e cursos pósgraduados para os agentes comunitários e diversos multiprofissionais dos cuidados primários de saúde, ela merece maior destaque uma vez que visava enfrentar o problema da "gestão afastada dos problemas do território", uma das questões que justificam a necessidade da reforma, e tem uma "orientação para a comunidade com estratégias ajustadas às necessidades locais”, princípio reformista fundador.

Como se depreende da epígrafe, Manguinhos foi um projeto catalisador de ações intersectoriais e constituíram bases locais para políticas de promoção da saúde. No entanto, ao transformar o território em espaço que integra intervenções relativas aos problemas/cuidados de saúde e determinantes sociais, articulando-se ao ensino e pesquisa, estimar sua efetividade se constituía um grande desafio para a avaliação. Em uma apreciação preliminar se constatava diferentes percepções e orientações no planejamento e gestão das ações pelos diversos atores envolvidos, e uma dificuldade de compreensão da avaliação de práticas assistenciais ligadas à promoção da saúde. Estas constatações eram agravadas pelas lacunas de conhecimento existentes na literatura sobre as abordagens avaliativas a serem utilizadas nas ações comunitárias.

É nesse contexto que, através do Programa de Cooperação entre a ENSP/Fiocruz, Canadian Public Health Association (CPHA) e ABRASCO, com o suporte financeiro da Associação Canadense para o Desenvolvimento Internacional (ACDI), que passamos a contar com a expertise da Cátedra de Abordagens Comunitárias e Iniquidades em Saúde (CACIS) da Universidade de Montreal, nessa área de conhecimento, coordenada por Louise Potvin. Nela se considera a promoção da saúde como um eixo a ser privilegiado na formação e investigação no campo da saúde pública em geral, particularizando-se como focos da avaliação a reorganização do sistema de cuidados e articulação intersetorial. A importância desta etapa, de integração recursiva de práticas-formação-pesquisa, mediando-se pelo "conceito" de espaço sociossanitário nos estudos avaliativos, serviram para documentar as colaborações entre parceiros de diversos setores e esferas de atividade mostrando também que as colaborações são conflituais já que os diferenciais de recursos e poder que estão na base das desigualdades sociais atravessam também estes espaços de ação. No entanto, a busca de solução das controvérsias inerentes a estas parcerias leva a inovações cuja emergência é facilitada pela pesquisa avaliativa que organiza espaços de reflexividade para o conjunto dos atores. Estas condições facilitam o dimensionamento e a institucionalização de soluções inovadoras que devem ser parte dos processos decisórios, contribuindo para que a avaliação seja um instrumento efetivamente utilizado para a redução das desigualdades sociais em saúde.

À guisa de conclusão, para não extrapolar "os caracteres", me permito remeter os leitores para a Antologia prefaciada por Paulo Buss, disponível em acesso aberto pelo projeto LEIASS (Linha Editorial de Apoio aos Sistemas de Saúde), uma parceria entre nosso Instituto e o CONASS para formação de recursos humanos nos PALOP, e espero que estimule também um convite à partilha de lições aprendidas com "atores territoriais".

\footnotetext{
${ }^{1}$ Instituto de Higiene e Medicina Tropical, Universidade Nova de Lisboa. R. Junqueira 96, Belém. 1349-008 Lisboa Portugal.zhartz@ihmt.unl.pt
} 


\section{Referências}

1. Buss P. Desenvolvimento local integrado e sustentável em Manguinhos (1993-2002): O início do processo. In: Hartz Z, Bodstein R e Potvin L, organizadores. Avaliação em Promoção da Saúde: Uma antologia comentada da parceria entre o Brasil e a Cátedra de Abordagens Comunitáriase Iniquidades em Saúde (CACIS), da Universidade de Montreal, de 2002 a 2012. Brasília: Conass; 2012. 